\title{
Malaria elimination strategy and challenges in People's Republic of China
}

\author{
Xiao-Nong Zhou*, Shu-Shen Zhou, Xia Zi-Guang \\ From Challenges in malaria research \\ Basel, Switzerland. 10-12 October 2012
}

\section{Background}

Malaria remains an infectious disease of foremost public health importance in the People's Republic of China. Historically, high malaria incidence rates have been reported from 24 provinces of P.R. China with more than 30 million cases annually reported. With the significant reduction of malaria incidence, the national malaria elimination was launched in 2010.

\section{Methods}

The risk factors related to malaria transmission in China was reviewed based on the previous literature reviewing, and the capacity of malaria elimination was analysed based on the readiness in surveillance and response system. The challenges and future research priorities related to the elimination strategy were put forward.

\section{Results}

Owing to large-scale control activities facilitated through primary healthcare networks and community participation, the infection rate of Plasmodium vivax has been reduced to under $0.01 \%$ in most areas of China, and $P$. falciparum malaria has been eliminated in most provinces, except Yunnan and Hainan. The elimination strategy formulation and its readiness analysis were performed with discussion on the challenges for the national malaria elimination programme in China, while the sourthern border areas in Yunnan will be the one of most hard issue to elimination the disease. Finally the recommendation on surveillance and response approaches based on currently satus leading to malaria elimination in China were put forward.

National Institute of Parasitic Diseases, China CDC, Shanghai 200025, P.R. China
Submit your next manuscript to BioMed Central and take full advantage of:

- Convenient online submission

- Thorough peer review

- No space constraints or color figure charges

- Immediate publication on acceptance

- Inclusion in PubMed, CAS, Scopus and Google Scholar

- Research which is freely available for redistribution 